\title{
EMOTIONAL INTELLIGENCE AND SELF EFFICACY AS PREDICTORS OF PSYCHOLOGICAL ADJUSTMENT AMONG SECONDARY SCHOOL ADOLESCENTS IN AWKA EDUCATION ZONE, NIGERIA
}

\author{
Oparaugo, Ursula Ifeoma ${ }^{1 \mathrm{i}}$, \\ Rose C. Ebenebe ${ }^{2}$ \\ ${ }^{1}$ Department of Educational Foundations, \\ Nnamdi Azikiwe University, \\ Awka, Anambra State, \\ Nigeria \\ 2Prof., Department of Educational Foundations, \\ Nnamdi Azikiwe University, \\ Awka, Anambra State, \\ Nigeria
}

\begin{abstract}
:
This study investigated emotional intelligence and self-efficacy as predictors of psychological adjustment among secondary school adolescents in Awka Education Zone, Anambra State. Three research questions guided the study and three null hypotheses were tested at 0.05 level of significance. The population of the study was 4,421 senior secondary two (SS2) students from 61 secondary schools in Awka Education Zone. The Sample size of the study comprises 485 SS2 obtained using simple random sampling technique. Three sets of questionnaire titled "Emotional Intelligence Questionnaire (EIQ), "Self Efficacy Questionnaire (SEQ) and "Psychological Adjustment Questionnaire (PAQ)" were used for data collection. The data obtained were analyzed using multiple regression analysis. The results of the study showed among others that emotional intelligence and self efficacy of students significantly predict their psychological adjustment. It was also revealed that there were positive relationship existing between adolescents' emotional intelligence, self efficacy and their psychological adjustment. Based on the findings, it was recommended among others, that parents and teachers should devote more time and put best efforts to empower their children and students to build good self-efficacy for promoting their psychological adjustment.
\end{abstract}

Keywords: emotional intelligence, self efficacy, psychological adjustment, adolescents

${ }^{i}$ Correspondence: email chidinnebedum@yahoo.com 


\section{Introduction}

Human development involves different stages which includes adolescence stage. An adolescent is a young person at the process of developing from childhood to adulthood. An adolescent is any person between age bracket of 10 and 19; those in the stage of adolescence. It is in this stage of human development that individuals develop to their full potentials in terms of cognitive knowledge and skills, as well as behavioural tendencies and inclinations. Adolescents are in that critical stage of human development where they need concerted attention of the home, school and general public so as to be comprehensively prepared for the future roles and responsibilities in the society. Therefore, the interests in studying adolescents point to the importance societies place on them.

Generations after generations have recognized the fact that adolescents are the future leaders of the society. Adolescents are the leaders of tomorrow; those who will carry on with the values and mores of the society. Moreover, adolescence stage is of significant importance because it is a transitional period between childhood and adulthood. As a transition period it has its attendant challenges given that new bio-social challenges begin to emerge. This supports Bandura's (2005) assertion that different periods of life have their unique challenges and competent demands for successful functioning and that changing aspirations, time perspectives, and societal systems over the course of life span alter how people structure, regulate, and evaluate their lives. Adolescents face many physiological, biological, psychological and social changes and successful adaptation to these changes demands that realignment takes place within the young person; and when these realignment mechanisms are not in place an adolescent is unable to confront and deal with a developmental challenge successfully which results in deleterious psychological, emotional and behavioural consequences.

The social changes of the adolescents have been increasing globally considering the age they find themselves. Adolescents are faced with lots of information and its pressure streaming from the social media. Nwosu, Grosser and Nwanguma (2015) described adolescents' as being buried under a crazy quilt of digital connections every single moment of every single night spending a great deal of their time on the computer, engaging in several online discussions at once, talking on a cell phone while waiting those interminable time for a response, listening to a burned CD, with a TV on in the background, and, naturally, focusing on homework at the same time. In this vein, Zarrett and Eccles (2006) have noted that some adolescents develop a set of personal assets that help them to successfully meet challenges they face and develop the skills, attitudes, values, and social capital they need for a successful transition into adulthood which have been pointed out to include, one's self belief system, emotional control, sense of optimism, and attachment to pro-social institutions. Developing a set of personal assets that help in coping with situations in life depends greatly on how well an individual is adjusted to his environment. 
Adjustment could simply be referred to as adaptive processes in which an individual tries to fit in into a particular circumstance which presents certain challenges. According to Salami (2011), adjustment is a condition or state in which one feels that one's needs have been (or will be) fulfilled and one's behaviors conforms to the needs of a given environment. It has been viewed as a process of maintaining harmonious relationships. It is a behavioural process by which humans maintain equilibrium among various needs or between their needs and obstacles of their environment (Ugodulunwa \& Anakwe, 2012). Adjustment can be viewed in psychological perspective.

Psychological adjustment is a process through which people manage or cope with the demands or challenges of everyday life; attempting to deal with stress, tension, conflicts while at the same time striving to maintain harmonious relationship with the environment (Raju \& Rahamtulla, 2007). What is very important in the issue of psychological adjustment is the fact that the individual needs to strive to maintain a state of equilibrium. There appears to be a challenge to overcome tension, stress and conflict while at the same time efforts are being made to live harmoniously with others in the society, and failure to do this may result in maladjustment. Psychological adjustment in this present work is defined as a behavioural process of balancing conflicting needs or needs challenged by obstacles in the environment. Humans and animals regularly adjust to their environment. For example, when they are stimulated by their psychological state to seek food they eat (if possible), to reduce their hunger and thus adjust to the hunger stimulus. However, adolescents have been reported to be struggling with challenges in the society that result in diverse adjustment problems which may lead to future mental/health problems. It becomes imperative that predictors of psychological adjustment be identified.

Recently, Aji, Ifedike, Emelumadu, Ubaka, Nwabueze and Azuike (2013) revealed that Nigerian adolescents engage in risk sexual activities, and they also engage in smoking and other illicit drugs. These scholars assert that there has been an increasing wave of crime rate perpetuated by adolescents. In recent times, there have also been cases of immoral behaviour among adolescents resulting from perceived failure in their endeavour (Imhonde \& Aluede, 2007). In the same like manner, it has also been observed that most adolescent students' in Awka, Anambra State engaged in cultism, smocking, sexual acts, get addicted to hard drugs and other social vices points to the fact that these adolescents may not be psychologically adjusted.

Psychological adjustment problem of adolescents may develop as a result of new challenges faced as they encounter physiological, emotional, and social changes. Some may be worried about the societal acceptance of their physical appearances, their cognitive abilities, peer acceptance, progress in their careers, and even parental demands. When these are not actually handled, psychological adjustment problems may ensue. Adolescents being faced with psychological adjustment problem might be a result of poor belief system such as low self-efficacy, since self-efficacy has to do with one's conviction of his ability to handle specific tasks. 
In literature many assumptions have been made pointing at emotional intelligence and self-efficacy as influential factors on psychological adjustment. According to Nishi and Komal (2018), emotional intelligence is the ability to manage feelings and pleasures of one and other people. Every individual's ability varies in precisely identifying, appraising and expressing their own emotions as well as the emotions experienced by others (Okonkwo, Chinweze \& Okafor, 2015). In the context of this present study, the researcher defines emotional intelligence as the ability to identify and manage one's emotions and the emotions of others. The researcher indicates that emotional intelligence begins with what is called "self" and "social awareness", the ability to recognize emotions and their impact in both oneself and others.

Adolescent with high emotional intelligence is supposed to be easily adjusted to the demands of the society. The individual finds it easier to form and maintain interpersonal relationships and to 'fit in' to group situations. The individual also has better understanding of his/her own psychological state, which can include managing stress to reduce depression. Studies indicate that emotional and social skills or empowerment of emotional intelligence occupies a great role in the quality improvement of personal and social relationships (Abadil, Zadegan, Gorgij \& Dadkan, 2014). This is very important in psychological adjustment since it has a lot to do with ones' ability to cope with stress, tension, and conflicts while at the same time the individual strives to maintain harmonious relationship with the environment. This made Gorostiaga, Balluerka, Aritzeta, Haranburu, and Alonso-Arbiol (2011) to assert that emotional intelligence is related to psychological and social adjustment.

Researches have shown that emotional intelligence correlates significantly with school adjustment of students, Punia and Sangwan (2011); it correlates with mental hygiene and social adjustment of mentally retarded children's parents (Abadi, Zandegan, Gorgij \& Dadkan, 2014); emotional intelligence also has positive relationship with selfesteem and negative relationship with depression of adolescents and psychological wellbeing of adolescents (Mehmood \& Gulzar, 2014). It has been shown to predict students' behaviours and attitudes Salami, (2011) and adolescent adjustment (Salguero, Palomera \& Fernandez-Berrocal, 2010).

Perhaps, one can attribute Nigerian adolescents' maladjustment to inappropriate manner in which adolescents seem to handle their emotions when they are faced with challenges. This is because adjustment in a way comprises successful maintenance of equilibrium in certain challenging situations which has a lot to do with control and regulation of one's emotions.

Self-efficacy, on the other hand, as earlier stated, attracted attention of eminent scholars in connection with human behaviour. It is perceived to have strong influence on peoples' style/ pattern of behaviour. Whatever behaviour an individual exhibits has a lot to do with his belief system and occupies a central role in the casual structured cognitive theory affecting adaptation and change through their impact on other determinants (Bandura, Barbaranelli, Capara, \& Pastorelli, 2001). In this present work, self-efficacy is conceived as an individual's belief in his or her innate ability to achieve goals. It refers as 
a key component of the self system, which consists of an individual's attitude, ability and cognitive resources. High self efficacy increases the likelihood of successfully achieving a given task.

Self-efficacy has been seen as thoughts or ideas people hold about their abilities to perform tasks that are necessary in accomplishing a desired outcome (Hall \&Vanice 2010). According to Luszczynska, Piko and Januszewicz (2014), self-efficacy is the optimistic beliefs about individual ability to deal with tasks at hand. Individuals with higher self-efficacy are likely to handle situations with calmness and hence may adjust to situations better than those who do not have high self-efficacy.

Bandura (1997) and Schunk (1995) noted that self-efficacy beliefs influence task choice, effort, persistence, resilience, and achievement. Lanpert, (2007) in his study has shown that self-efficacy significantly predicted grade point average for college students and that with stress; self-efficacy explained more than half of the variance on anxiety and depression. In spite of the potential insight that studies on emotional intelligence and self-efficacy, as predictors of adolescents' psychological adjustment could give in intervention strategies for curbing adolescent behavioural problems emanating from psychological maladjustment, there appears to exist insufficient predictive studies in this area on Nigerian adolescents. This made this researcher to set out to investigate emotional intelligence and self-efficacy as predictors of adolescents' psychological adjustment among secondary schools adolescents.

\section{Statement of Problem}

It has long been speculated that some reasonable proportion of Nigerian adolescent students, which includes, adolescents in Awka, Anambra state, engage in immoral acts. For instance, some of the adolescents engage in smoking cigarette and indulge in drinking all other kinds of hard drugs. Some others engage in sexual acts, cultism and other immoral activities. It's believed that such permissiveness, loose and destructive life style could lead to psychological maladjustment among these adolescents. An adolescent student who becomes maladjusted could become delinquent and violent with consequent adverse effects for himself, family and society at large. The adolescent educational pursuit could be terminated, and the individual becomes a nuisance to his family, community, and large society. In view of all these, one begins to wonder if the deviant behaviours seen among adolescent students could be indication of poor social adjustment, stem out of the pattern of their emotional intelligence or due to their level self efficacy. Hence, this study was designed to find out if emotional intelligence and self efficacy jointly predict psychological adjustment among secondary school adolescent students in Awka, Anambra state. 


\subsection{Purpose of the Study}

The main purpose of the study is to find out the predictive power of emotional intelligence and self-efficacy on the psychological adjustments of secondary school adolescents in Awka, Education Zone. Specifically, it sought to find out weather:

1) Emotional intelligence predicts psychological adjustments of secondary school adolescents in Awka, Education Zone.

2) Self efficacy predicts psychological adjustments of secondary school adolescents in Awka, Education Zone.

3) Emotional intelligence and self-efficacy jointly predict psychological adjustments of secondary school adolescents in Awka, Education Zone.

\subsection{Research Questions}

The following questions guided the study

1) How does emotional intelligence predict psychological adjustments of secondary school adolescents in Awka, Education Zone?

2) How does self efficacy predict psychological adjustments of secondary school adolescents in Awka, Education Zone?

3) How does emotional intelligence and self-efficacy jointly predict psychological adjustments of secondary school adolescents in Awka, Education Zone?

\subsection{Hypotheses}

The following hypotheses were formulated and were tested at 0.05 level of significance.

1) Adolescents' emotional intelligence is not a significant predictor of their psychological adjustment.

2) Adolescents' self efficacy is not a significant predictor of their psychological adjustment.

3) Adolescents' emotional intelligence and self efficacy are not jointly significant predictors of their psychological adjustment.

\section{Method}

A correlation research design was adopted for this study. The area of this study was Awka Education Zone in Anambra State. The population of the study consists of all 4,421 senior secondary two (SS2) students in Awka Education zone. The sample size for this study was 485 SS2 students (224 males and 261 females) drawn using multi-stage sampling procedure involving stratified and simple random sampling technique.

The instrument for data collection was the questionnaire of which there are three different ones: viz. Emotional Intelligence Questionnaire (EIQ), Self- Efficacy Questionnaire (SEQ) adapted from Sheker et al. and Psychological Adjustment Questionnaire (PAQ) adapted from Bronstein and Phyllis. The instrument was subjected to face validation using three experts comprising one in Educational Psychology, another in Guidance and Counseling and the third in Measurement and Evaluation, all from 
Faculty of Education, Nnamdi Azikiwe University Awka. Based on their inputs and comments, the researchers re-organized, restructured and modified the items which were used in carrying out the study. Cronbach's alpha procedure for testing reliability was applied which yielded coefficient of 0.85 for EIQ, 0.77 for SEQ and 0.76 for PAQ. The copies of the questionnaire were distributed to the respondents by the researchers with the aid of two briefed assistants using direct delivery technique. Multiple regression analysis was used in analyzing the data collected.

\section{Results}

Research Question 1: How does emotional intelligence predicts psychological adjustments of secondary school adolescents in Awka, Education Zone?

Table 1: Regression Coefficient $\mathrm{r}$ on Emotional Intelligence and Psychological Adjustment of Secondary School Adolescents

\begin{tabular}{|c|c|c|c|c|c|}
\hline Model & R & R Square & Adjusted R Square & Std. Error of the Estimate & Remarks \\
\hline 1 & .512 & .212 & .211 & 2.125 & Strong \\
\hline
\end{tabular}

As shown on Table 1, correlation coefficient between emotional intelligence and psychological adjustment of school adolescents is .512 with a coefficient of determination of .212. This shows that $21.2 \%$ variation in school adolescents' psychological adjustment can be attributed to emotional intelligence. The regression Coefficient $r$ of .512 indicated that emotional intelligence is a strong predictor of psychological adjustment of secondary school adolescents in in Awka Education Zone.

Research Question 2: How does self efficacy predicts psychological adjustments of secondary school adolescents in Awka, Education Zone?

Table 2: Regression Coefficient $r$ on Self Efficacy and Psychological Adjustment of Secondary School Adolescents

\begin{tabular}{|c|c|c|c|c|c|}
\hline Model & R & R Square & Adjusted R Square & Std. Error of the Estimate & Remarks \\
\hline 1 & .192 & .186 & .185 & 2.1001 & Moderate \\
\hline
\end{tabular}

As shown on Table 2, correlation coefficient between self efficacy and psychological adjustment of school adolescents is .192 with a coefficient of determination of .186. This shows that $18.6 \%$ variation in school adolescents' psychological adjustment can be attributed to emotional intelligence. The regression coefficient $r$ of .192 indicated that self efficacy is a moderate predictor of psychological adjustment of secondary school adolescents in in Awka Education Zone.

Research Question 3: How do emotional intelligence and self efficacy jointly predict psychological adjustments of secondary school adolescents in Awka, Education Zone? 
Table 3: Regression Coefficient $r$ on Emotional Intelligence,

Self Efficacy and Psychological Adjustment of Secondary School Adolescents

\begin{tabular}{|c|c|c|c|c|}
\hline Model & $\mathbf{R}$ & $\mathbf{R}^{\mathbf{2}}$ & Adjusted $\mathbf{R}^{\mathbf{2}}$ & Std. Error of Estimate \\
\hline 1 & $.138^{\mathrm{a}}$ & .019 & .015 & 10.230 \\
\hline
\end{tabular}

Table 3 shows that the correlation coefficient between emotional intelligence, self efficacy and psychological adjustment of school adolescents is .138 with a coefficient of determination of .019 . This shows that $1.9 \%$ of the variance in the psychological adjustment of the adolescent secondary school students is jointly predicted by their emotional intelligence and self-efficacy. The regression Coefficient $r$ of .138 indicated that emotional intelligence and self efficacy are jointly moderate predictor of psychological adjustments of secondary school adolescents in in Awka Education Zone.

Hypothesis One: Emotional intelligence is not a significant predictor of psychological adjustments of secondary school adolescents in in Awka Education Zone.

Table 4: Test of Significance of Simple Regression Analysis with Emotional Intelligence as Predictor of Psychological Adjustments of Secondary School Adolescents

\begin{tabular}{|l|c|c|c|c|c|}
\hline Predictor & $\mathbf{R}$ & $\mathbf{R}^{2}$ & $\boldsymbol{F}$ & P-value & Remark \\
\hline Emotional Intelligence & .512 & .212 & 235.544 & .0200 & ${ }^{*}$ S \\
\hline${ }^{*}$ Significant
\end{tabular}

As shown on Table 4, the simple regression coefficient ( $R$ ) is .512 while the $R^{2}$ is .212 showing that emotional intelligence makes $21.2 \%$ contribution to the variance in secondary school adolescents' psychological adjustments. The $F(1 / 485)=235.544$ and the $p$-value of .0200 is less than .05. Therefore, since the $p$-value is less than the stipulated .05 level of significance, the null hypothesis was rejected. Therefore, emotional intelligence is a significant predictor of psychological adjustments of secondary school adolescents in Awka Education Zone.

Hypothesis Two: Self efficacy is not a significant predictor of psychological adjustments of secondary school adolescents in in Awka Education Zone.

Table 5: Test of Significance of Simple Regression Analysis with Self Efficacy as Predictor of Psychological Adjustments of Secondary School Adolescents

\begin{tabular}{|l|c|c|c|c|c|}
\hline Predictor & $\mathbf{R}$ & $\mathbf{R}^{2}$ & $\boldsymbol{F}$ & P-value & Remark \\
\hline Self Efficacy & .192 & .186 & 213.322 & .0044 & ${ }^{*}$ S \\
\hline${ }^{*}$ Significant
\end{tabular}

As shown on Table 5, the simple regression coefficient (R) is .192 while the $R^{2}$ is .212 showing that self efficacy makes $18.6 \%$ contribution to the variance in secondary school adolescents' psychological adjustments. The $F(1 / 485)=213.322$ and the $p$-value of .0044 is less than .05. Therefore, since the $p$-value is less than the stipulated .05 level of 
significance, the null hypothesis was rejected. Therefore, self efficacy is a significant predictor of psychological adjustments of secondary school adolescents in Awka Education Zone.

Hypothesis Three: emotional intelligence and self efficacy are not jointly significant predictor of psychological adjustments of secondary school adolescents in Awka Education Zone.

Table 6: Test of Significance of Simple Regression Analysis with Emotional Intelligence and Self Efficacy as Predictor of Psychological Adjustments of Secondary School Adolescents

\begin{tabular}{|l|c|c|c|c|c|}
\hline Predictor & $\mathbf{R}$ & $\mathbf{R}^{2}$ & $\boldsymbol{F}$ & $\boldsymbol{P}$-value & Remark \\
\hline Emotional Intelligence and Self Efficacy & .138 & .019 & 4.682 & .0010 & ${ }^{*} \mathrm{~S}$ \\
\hline${ }^{*}$ Significant
\end{tabular}

As shown on Table 10, the simple regression coefficient $(R)$ is .138 while the $R^{2}$ is .019 showing that emotional intelligence and self efficacy makes $1.9 \%$ contribution to the variance in secondary school adolescents' psychological adjustments. The $F(1 / 485)=$ 4.682 and the $p$-value of .0010 is less than 0.05 . Therefore, since the $p$-value is less than the stipulated .05 level of significance, the null hypothesis was rejected. Therefore, emotional intelligence and self efficacy are jointly significant predictors of psychological adjustments of secondary school adolescents in Awka Education Zone.

\section{Discussion}

The result of this study revealed that emotional intelligence is a strong predictor of psychological adjustment of secondary school adolescents in in Awka Education Zone. This is supported by the finding of Busari (2013) which showed that emotional intelligence is a unique predictor of psychological adjustment. This possible explanation for this finding is probably due to the fact that individuals that monitor their feelings and that of people around can easily adjust psychologically Adolescents who possess high emotional intelligence can easily adjust to changing situations. They can effectively use their emotions to aid cognitive processes that promote their psychological adjustment. Further results shows that emotional intelligence is a significant predictor of psychological adjustments of secondary school adolescents in Awka Education Zone. This is in conformity with the finding of Salguero, Palomera and Fernadez-Berrocal (2012) which showed that emotional intelligence is significant predictor of psychological adjustment in adolescents:

The finding of the study shows that self efficacy is a moderate predictor of psychological adjustment of secondary school adolescents in Awka Education Zone. This is in consonance with the finding of Gebregergis, Tekie. Yikealo and Habte (2019) who reported that self-efficacy was positively related to psychological adjustment. Perhaps, the reason for the finding may be due to the fact that adolescents who beliefs in their abilities to manipulate situation can easily adjust psychologically in an environment. Self- 
efficacy installs high confidence in adolescents to face any situation that could affect their psychological adjustment. It was also found out that self efficacy is a significant predictor of psychological adjustments of secondary school adolescents in Awka Education Zone. This is in agreement with the finding of Yusliza (2011) which revealed that self-efficacy is significantly related with psychological adjustment of students. adolescents who possess high self-efficacy strive overcome challenging situations to significantly ensure and maintain their psychological adjustment.

It was reported that emotional intelligence and self efficacy are jointly moderate predictor of psychological adjustment of secondary school adolescents in in Awka Education Zone. This supported the finding of Salami (2011) which showed that selfefficacy and emotional intelligence are joint predictors of students' psychological adjustment. The possible reason for the finding is that adolescents who possess good emotional intelligence and self efficacy can take desirable actions that foster their psychological adjustment in a given situation. Adolescents' emotional intelligence and self efficacy direct and regulate their actions toward promoting their psychological adjustment. It was also revealed that emotional intelligence and self efficacy are jointly significant predictors of psychological adjustments of secondary school adolescents in Awka Education Zone. This is in line with the finding of Adeyemo and Adeleye (2008) who reported that emotional intelligence and self efficacy have significant relationship with psychological adjustments (wellbeing) of secondary school students.

\section{Conclusion}

Based on the findings, it was concluded that emotional intelligence and self efficacy are significant predictors of psychological adjustment of secondary school adolescents in in Awka Education Zone. Emotional intelligence and self efficacy shape the thoughts, feelings and behaviours of adolescents which contribute to their psychological adjustments. Emotional intelligence and self efficacy stimulates adolescents to face difficulties to enable them adjust in their environment. The confidence of adolescents to overcome the obstacle to the psychological adjustment emanates from their emotional intelligence and self efficacy.

\subsection{Recommendations}

Based on the findings, it was recommended among others that

1) Parents and teachers should devote more time and put best efforts to empower their children and students to build good self-efficacy for promoting their psychological adjustment.

2) School counsellors should assist students with low emotional intelligence to overcome their problem and enhance their psychological adjustment.

\section{Conflict of Interest Statement}

The authors declare no conflict of interest. 


\section{About the Authors}

Oparaugo, Ursula Ifeoma is a lecturer in the Department of Educational Foundations in Nnamdi Azikiwe University, Awka. She holds a master degree in Educational Psychology and currently a PhD scholar in the above department.

Prof. Rose C. Ebenebe is profession in the Department of Educational Foundations in Nnamdi Azikiwe University, Awka. She has numerous publications in reputable national and international journals. Prof. Rose has attended several conferences inside and outside Nigeria and also served as the lead paper presenters in several conferences. She has successfully supervised all over $40 \mathrm{PhD}$ dissertation and over $85 \mathrm{M}$.Ed theses. Most of the supervised PhD candidates are now professors in different universities.

\section{References}

Abadi H.J., Zadegan A.I, Gorgij H.C. \& Dadkan A.A. (2014). The relationship between Emotional Intelligence, Mental Hygiene and social Adjustment of mentally Retarded Children's Parents and Normal Children's. International Journal of Psychology and Behavioral Research, 4(3),6-10.

Adeyemo, D.A. \& Adeleye, A.T. (2008). Emotional intelligence, religiosity and self efficacy as predictors of psychological well-being among secondary school adolescents in Ogbomoso, Nigeria. European Journal of Psychology, 4(1), 13-16.

Aji, J, Aji, M.O., Ifedike C.O., Emelumadu O.F., Ubaka C., Nwabueze S.A. \& Azuike E.C. (2013). Adolescent Sexual Behaviour and Practices in Nigeria. A Twelve year Renewiew AFICIMEDDIC Journal, 4 (1), 35-42.

Bandura, A., Barbaranelli, C., Capara, G. V., \& Pastorelli, C. (2001). Self-Efficacy beliefs as shapers of children's aspirations and career trajectories. Child Development, 72(1), 13-18.

Bandura, A. (2005). The evolution of social cognitive theory. In K. G. Smith \& M.A. Hitt (Eds) Great Minds in Management (p.1) Oxford University Press.

Bandura, A. (1997). Self-efficacy: The exercise of control. New York: Freeman.

Busari, A.O. (2013). Emotional intelligence: A predictor of psychological adjustment to anxiety and depression among Nigerian adolescents. Nigerian Journal of Guidance and Counselling, 18(1), 27-31.

Gorostiaga, A. Balluerka, N., Aritzeta, A., Haranburu, M. \& Alonso-Arbiol, I. (2011). Measuring perceived emotional intelligence in adolescent population: Validation of the Short Trait Meta-Mood Scale (TMMS-23). International Journal of Clinical and Health Psychology, 11(3), 523-537

Gebregergis, W.T., Tekie, D., Yikealo, D. and Habte, A. (2019). Antecedents of psychological adjustment of international students studying in China: The roles of self-efficacy and self-esteem. Open Journal of Social Sciences, 7(1), 233-235.

Hall, S. \& Vance, E. A. (2010). Improving self-efficacy in Statistics: Role of self-explanation and feedback. Journal of Statistics Education, 18 (3), 1-22. 
Lampert, Joel N. (2007). The Relationship of Self-Efficacy and Self-Concept to academic performance in a College Sample: Testing Competing Models and Measures Master's thesis, Pacific University. Retrieved from: http://commons.pacificu.edu/spp/86

Luszczynska, A., Piko, B. \& Januszewicz, A. (2014). Self-efficacy and adolescent's health. In R.J.R. Levesque (ed.), Encyclopedia of adolescences. New York, Ny: Springer.

Nishi, T. \& Komal, P. (2018). A study of emotional intelligence of adolescent students of senior secondary schools in relation to their sex and locale. International Journal of Research and Analytical Reviews, 5(3), 1589-1596.

Nwosu, Grosser and Nwanguma (2015). Conference paper: Deal versus realities of adolescent learning in the $21^{\text {st }}$ century; An examination of the role of Cognitive education (COGED) in preparing adolescents for $21^{\text {st }}$ century challenging

Okonkwo, E.A., Chinweze, U.C. \& Okafor, C.O. (2015).Emotional intelligence and selfefficacy as predictors of life satisfaction among police officers. Journal of Social Sciences and Public Policy, 7(1), 24-32.

Raju, M. V.R., \& Rahamtull T.K. (2007).Adjustment problems among school students Journal of Indian Academic of Applied Psychology33(1), 73-79.

Salami, S.O. (2011). Psychosocial predictors of adjustment among first year college of education students. US-China Education Review, 8(2), 239-248.

Salguero, J.M., Palomera, R. \& Fernadez-Berrocal, P. (2012). Perceived emotional intelligence as predictor of psychological adjustment in adolescents: A 1-year prospective study. European Journal of Psychology of Education, 27(1), 21-34.

Ugodulunwa C.A. \& Anakwe A.I., (2012). Factoria validity of a school adjustment, school of adolescents in Metanu State. The Educational Psychologiest,6(1), 30-88.

Yusliza, M.Y. (2011). Self-efficacy, perceived social support, and psychological adjustment in international students in a public higher institution in Malaysia. Journal of Studies in International Education, 2(12), 34-40.

Zarret, N., Peck S. C., Eccles J. S., (2006). The effects of activity participation on development trajectories. In: Roth J. L., Hanson D. M. editors adolescents organized activity participation pattern: Differing developmental potentials, Symposium conducted at the biennial meeting of the society for Research on Adolescence; San Francisco, CA. 
Creative Commons licensing terms

Author(s) will retain the copyright of their published articles agreeing that a Creative Commons Attribution 4.0 International License (CC BY 4.0) terms will be applied to their work. Under the terms of this license, no permission is required from the author(s) or publisher for members of the community to copy, distribute, transmit or adapt the article content, providing a proper, prominent and unambiguous attribution to the authors in a manner that makes clear that the materials are being reused under permission of a Creative Commons License. Views, opinions and conclusions expressed in this research article are views, opinions and conclusions of the author(s). Open Access Publishing Group and European Journal of Education Studies shall not be responsible or answerable for any loss, damage or liability caused in relation to/arising out of conflicts of interest, copyright violations and inappropriate or inaccurate use of any kind content related or integrated into the research work. All the published works are meeting the Open Access Publishing requirements and can be freely accessed, shared, modified, distributed and used in educational, commercial and non-commercial purposes under a Creative Commons Attribution 4.0 International License (CC BY 4.0). 